\title{
Validity of pulse oximetry in detection of hypoxaemia in children: comparison of ear, thumb and toe probe placements
}

\author{
N. Bilan, ${ }^{1}$ A. G. Behbahan, ${ }^{2}$ B. Abdinia ${ }^{2}$ and M. Mahallei ${ }^{2}$
}

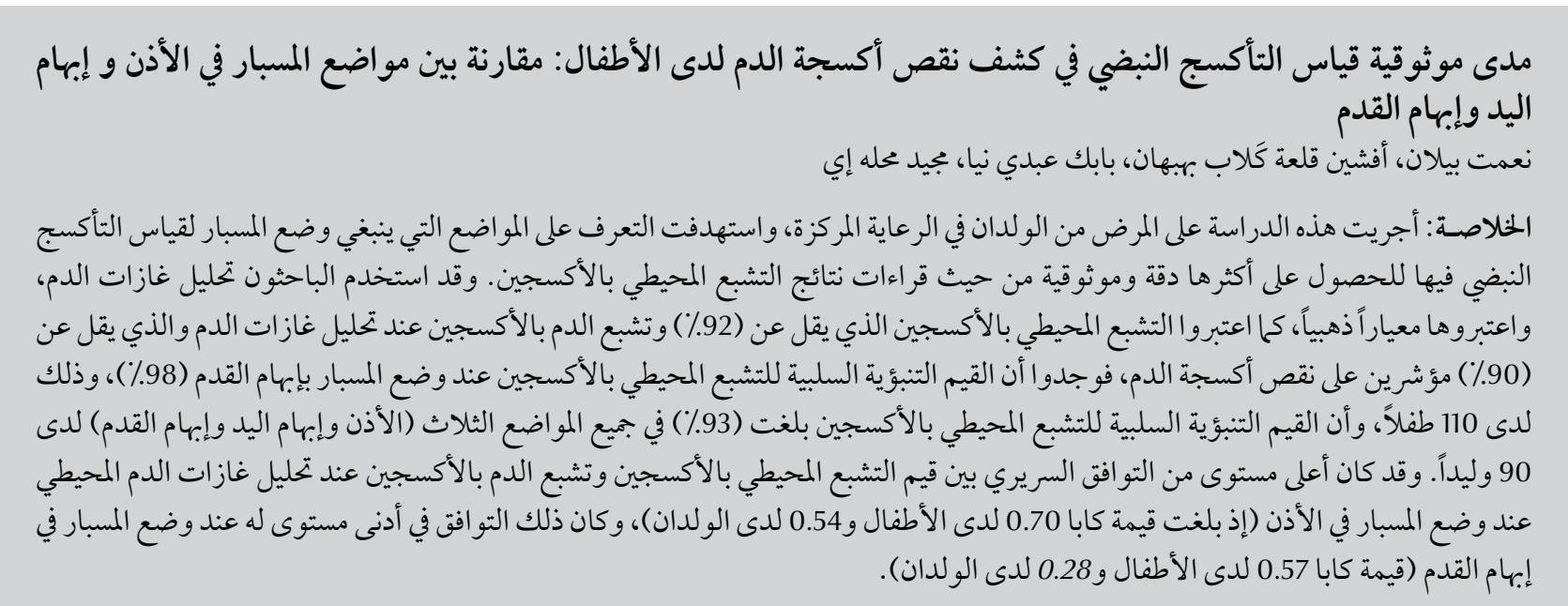

ABSTRACT This study of paediatric intensive care patients aimed to determine where pulse oximetry probes should be placed to obtain the most accurate and reliable readings of peripheral oxygen saturation $\left(\mathrm{SpO}_{2}\right)$. Using arterial blood gas analysis $\left(\mathrm{SaO}_{2}\right)$ as the gold standard and $\mathrm{SpO}_{2}<92 \%$ and $\mathrm{SaO}_{2}<90 \%$ as indicators of hypoxaemia, negative predictive values of $\mathrm{SpO}_{2}$ were $96 \%, 98 \%$ and $98 \%$ at the ear, thumb and big toe respectively in 110 children, and $93 \%$ at all 3 sites in 90 neonates. The highest clinical agreement between $\mathrm{SaO}_{2}$ and $\mathrm{SpO}_{2}$ was for ear probes in children $(\kappa=0.70)$ and the lowest was for big toe probes $(\kappa=0.57$ and 0.28 in children and neonates respectively).

Validité de l'oxymétrie de pouls pour détecter l'hypoxémie chez l'enfant : comparaison du placement de la sonde au niveau de l'oreille, du pouce et de l'orteil

RÉSUMÉ La présente étude sur les patients en soins intensifs néonataux a pour objectif de définir l'emplacement de la sonde oxymétrique afin d'obtenir les relevés les plus fiables et les plus précis de la saturation en oxygène $\left(\mathrm{SpO}_{2}\right)$. En utilisant l'analyse des gaz du sang artériel $\left(\mathrm{SaO}_{2}\right)$ comme méthode de référence associée à une $\mathrm{SpO}_{2}<$ $92 \%$ et à une $\mathrm{SaO}_{2}<90 \%$ comme indicateurs d’hypoxémie, les valeurs prédictives négatives de $\mathrm{SpO}_{2}$ étaient de $96 \%, 98 \%$ et $98 \%$ au niveau de l'oreille, du pouce et du gros orteil, respectivement chez 110 enfants, et de $93 \%$ aux trois endroits chez 90 nouveau-nés. La sonde auriculaire a permis d'obtenir la meilleure corrélation clinique entre la $\mathrm{SaO}_{2}$ et la $\mathrm{SpO}_{2}$ chez l'enfant $(\kappa=0,70)$ alors que la sonde au niveau du gros orteil a recueilli les moins bons résultats ( $\kappa=0,57$ et 0,28 , chez l'enfant et le nouveau-né respectivement).

${ }^{7}$ Tuberculosis and Lung Diseases Research Centre; ${ }^{2}$ Department of Paediatrics, Tabriz Children's Hospital, Tabriz University of Medical Sciences, Tabriz, Islamic Republic of Iran (Correspondence to N. Bilan: bilan@tbzmed.ac.ir).

Received: 03/06/07; accepted: 16/10/07 


\section{Introduction}

Pulse oximetry is a noninvasive technique of measuring oxygenation of the blood that is used worldwide to assess critically ill patients, especially in intensive care units and operating rooms. Its advantages include the early detection of hypoxia and hyperoxia, less frequent need for blood sampling for blood gas analysis, determination of the required fraction of inspiratory $\mathrm{O}_{2}$ and support for the process of ventilator weaning [1-3]. The use of pulse oximetry in the operating room has revealed that preoperative hypoxaemia is much more prevalent than was previously supposed [4] and, although there is no definitive evidence, the generalized use of pulse oximetry may have contributed to decreased morbidity and mortality rates of the preoperative period.

Monitoring of peripheral oxygen saturation $\left(\mathrm{SpO}_{2}\right)$ by pulse oximetry can be done either continuously or intermittently (spot check) depending on the clinical status of the patient [5]. All types of pulse oximeters operate on the Beer-Lambert law of spectral analysis based on light absorption [6,7]. The performance of the pulse oximeter can be disrupted by several factors including: poor peripheral perfusion, peripheral vasoconstriction, hypotension, low pulse pressure and patient's motion [8]. In clinical practice, many sites are used for pulse oximetry probe placement, including the nasal septum, ear lobe, thumb and big toe. A study on 13 adult patients showed that significant delays in the detection of acute hypoxaemia by pulse oximetry occurred when the probe was placed at the toe compared with probes at either the ear or finger [9].

We could not find any similar study in the available medical literature to determine the most appropriate site for pulse oximetry probe placement in newborns and children. This study was therefore designed to evaluate simultaneous $\mathrm{SpO}_{2}$ levels recorded by pulse oximetry from probes placed on ear, thumb and big toe of paediatric patients and to compare the validity of the results with arterial blood gas $(A B G)$ analysis.

\section{Methods}

In this cross-sectional comparative study we compared the readings from 3 different types of pulse oximetry probes/placements (ear, thumb and big toe) and assessed their validity in detecting hypoxaemia by comparing the results with those of $A B G$ analysis as the gold standard for diagnosis of blood gas disorders.

\section{Sample}

The sample was 200 paediatric patients: 90 newborn infants (aged $<1$ month) and 110 children (aged $1+$ months). Sampling was done by a simple consecutive method covering all patients who were admitted to the paediatric intensive care unit (PICU) or neonatal intensive care unit (NICU) of Tabriz Children's Hospital during a 1-year period from 1 November 2004 to 31 October 2005. Of the 216 children admitted, we enrolled only 200 in the study who needed simultaneous blood sampling for ABG analysis and pulse oximetry during their treatment. Therefore no children underwent unnecessary blood sampling or any other test for completion of the study. We also excluded those patients whose tests were suggestive of a technical error. Therefore 16 children were finally excluded from this study.

\section{Data collection}

The Novametrix pulse oximeter (Novametrix Medical Systems, Connecticut, USA) and GEM-3000 blood gas analyser (Instrumentation Laboratory, Massachusetts, USA) were used. For blood gas analysis, arterial blood was drawn from radial or brachial arteries, and international standard laboratory protocols for blood gassampling, sample transport and analysis were adhered to.
Pulse oximetry was recorded simultaneously on 3 different probe placement sites in each patient (ear, thumb and big toe) by a trained nurse or a paediatric resident using a specially structured probe for each site.

The research review board and ethics committee of Tabriz University of Medical Sciences approved the study. However, the method imposed no additional cost or harm on participants and there was therefore no need to obtain special written permission from parents.

\section{Analysis}

The validity of pulse oximetry in the detection of hypoxaemia was determined by comparing the results with those of simultaneous ABG analysis (gold standard); $\mathrm{SpO}_{2}<92 \%$ and arterial oxyhaemoglobin saturation $\left(\mathrm{SaO}_{2}\right)<90 \%$ were considered indicators of hypoxaemia in the study. Statistical analysis of data was done using standard formulae (sensitivity, specificity and positive and negative predictive values). The bias was calculated for both age groups (neonates and children) using the following equation: bias $=\mathrm{SpO}_{2}-\mathrm{SaO}_{2}$, We also determined the accuracy of the bias, which is equal to the standard deviation (SD). Clinical agreement was calculated by the kappa test using the following cut-offs: $\kappa \leq 0.20$ (negligible or little agreement); 0.20 $<\kappa \leq 0.40$ (minimal agreement); 0.40 $<\kappa \leq 0.60$ (moderate agreement); 0.60 $<\kappa \leq 0.80$ (good agreement); $\kappa>0.80$ (excellent agreement).

\section{Results}

The mean age of the children was 42 (SD 40) months and of the neonates was 7.5 (SD 6.0) days. The mean haemoglobin level was 11.8 (SD 2.2) g/dL in children and 12.9 (SD 2.6) g/dL in neonates. The mean recorded values of $\mathrm{SaO}_{2}, \mathrm{SpO}_{2}$ and the bias in both groups are shown in Table 1. The mean $\mathrm{SaO}_{2}$ was 94.6 (SD 2.3) and 94.4 (SD 3.0) in children and neonates, respectively. 


\begin{tabular}{|c|c|c|c|c|c|c|c|}
\hline \multicolumn{8}{|c|}{$\begin{array}{l}\text { Table } 1 \text { Mean recorded values of arterial oxyhaemoglobin saturation }\left(\mathrm{SaO}_{2}\right) \text { by blood gas analysis and peripheral oxygen } \\
\text { saturation }\left(\mathrm{SpO}_{2}\right) \text { by pulse oximetry on } 3 \text { parts of the body in children and neonates }\end{array}$} \\
\hline \multirow[t]{3}{*}{ Age group } & \multirow{3}{*}{$\begin{array}{c}\mathrm{SaO}_{2} \\
(\mathrm{mmHg}) \\
\text { Mean (SD) }\end{array}$} & \multicolumn{3}{|c|}{$\mathrm{SpO}_{2}(\mathrm{mmHg})$} & \multicolumn{3}{|c|}{ Bias $(\mathrm{mmHg})$} \\
\hline & & Ear & Thumb & Big toe & Ear & Thumb & Big toe \\
\hline & & Mean (SD) & Mean (SD) & Mean (SD) & Mean (SD) & Mean (SD) & Mean (SD) \\
\hline Children & $94.6(2.3)$ & $95.9(3.1)$ & $93.7(3.3)$ & $92.6(5.4)$ & $0.02(3.71)$ & $-0.82(3.43)$ & $-1.94(3.18)$ \\
\hline Neonates & $94.4(3.0)$ & $96.8(2.2)$ & $95.4(3.2)$ & $94.8(2.4)$ & $1.53(3.42)$ & $0.22(3.84)$ & $-0.45(3.90)$ \\
\hline
\end{tabular}

$S D=$ standard deviation .

In the children the mean bias of pulse oximetry readings was 0.02 (SD 3.71), -0.82 (SD 3.43) and -1.94 (SD 3.18) at the ear, thumb and big toe respectively. In the neonates the mean bias of pulse oximetry was 1.53 (SD 3.42), 0.22 (SD 3.84) and -0.45 (SD 3.9) at the ear, thumb and big toe respectively.

The number of hypoxaemic cases detected by simultaneous pulse oximetry in the 3 parts of the body and $A B G$ analysis in children and newborn infants are shown in Table 2. The sensitivity, specificity and positive and negative predictive values, as well as the results of the $\mathrm{k}$-test in children and newborn infants, are shown in Table 3. Sensitivity was $67 \%, 83 \%$ and $83 \%$ and specificity was $98 \%, 92 \%$ and $90 \%$ for probes at ear, thumb and big toe respectively. Negative predictive values of $\mathrm{SpO}_{2}$ were $96 \%$, $98 \%$ and $98 \%$ at the ear, thumb and big toe respectively in the children, and $93 \%$ at all sites in the newborns. The highest clinical agreement between $\mathrm{SaO}_{2}$ and $\mathrm{SpO}_{2}$ was for ear probes $(\kappa=0.70$ and 0.54 in children and neonates respectively) and the lowest was for big toe probes ( $\kappa=0.57$ and 0.28 respectively).

\section{Discussion}

The role of pulse oximetry in the early detection of hypoxaemia has been emphasized by many studies. Moller et al. revealed that hypoxaemia can be diagnosed in patients monitored by pulse oximetry 19 times more frequently than in those without it [10]. Progressive utilization of pulse oximetry especially in PICUs has not only resulted in more frequent and earlier detection of hypoxaemia, but also diminished the need for repetitive blood gas analysis and its associated cost and complications.

\begin{tabular}{|c|c|c|c|c|c|}
\hline $\begin{array}{l}\text { Table } 2 \text { Numb } \\
\text { on } 3 \text { parts of } \\
\text { analysis as th }\end{array}$ & $\begin{array}{l}\text { f hypoxaer } \\
\text { ody in chi } \\
\text { d standaro }\end{array}$ & $\begin{array}{l}\text { cases dete } \\
\text { en and neo }\end{array}$ & $\begin{array}{l}\text { by simult } \\
\mathrm{s} \text { versus a }\end{array}$ & $\begin{array}{l}\text { ous pulse } \\
\text { ial blood }\end{array}$ & $\begin{array}{l}\text { metry } \\
\text { ABG) }\end{array}$ \\
\hline Age group/ & Com & ison of pulse & (imetry ver & ABG & Total \\
\hline probe site & $\begin{array}{c}\text { True } \\
\text { positives }\end{array}$ & $\begin{array}{c}\text { True } \\
\text { negatives }\end{array}$ & $\begin{array}{c}\text { False } \\
\text { positives }\end{array}$ & $\begin{array}{c}\text { False } \\
\text { negatives }\end{array}$ & \\
\hline & No. & No. & No. & No. & No. \\
\hline Children & & & & & \\
\hline Ear & 8 & 96 & 2 & 4 & 110 \\
\hline Thumb & 10 & 90 & 8 & 2 & 110 \\
\hline Big toe & 10 & 88 & 10 & 2 & 110 \\
\hline Neonates & & & & & \\
\hline Ear & 4 & 80 & 0 & 6 & 90 \\
\hline Thumb & 6 & 76 & 2 & 6 & 90 \\
\hline Big toe & 2 & 74 & 8 & 6 & 90 \\
\hline
\end{tabular}

$\mathrm{SpO}_{2}<92 \%$ and $\mathrm{SaO}_{2}<90 \%$ were considered as indicators of hypoxaemia: true positive: both $\mathrm{SpO}_{2}<92 \%$ and $\mathrm{SaO}_{2}<90 \%$; true negative: both $\mathrm{SpO}_{2} \geq 92 \%$ and $\mathrm{SaO}_{2} \geq 90 \%$; false positive: $\mathrm{SpO}_{2}<92 \%$ but $\mathrm{SaO}_{2}$ $\geq 90 \%$; false negative: $\mathrm{SpO}_{2} \geq 92 \%$ but $\mathrm{SaO}_{2}<90 \%$.
Our main goal was to determine where the pulse oximetry probes should be placed in patients admitted to the NICU and PICU to obtain the most accurate and reliable readings of $\mathrm{SpO}_{2}$ compared with $\mathrm{ABG}$ as the gold standard. Our study showed that $\mathrm{SpO}_{2}$ at the big toe had the lowest clinical agreement with $\mathrm{SaO}_{2}$ in both neonates and children. This is similar to the findings of a previous study on healthy volunteers by Hamber et al., who noted that significant delays occurred in the detection of acute hypoxaemia by pulse oximetry when the probe was placed at the toe compared with probes at the ear or finger. They declared that if hypoxaemia is defined as $\mathrm{SpO}_{2}<90 \%$, the mean delay time for detection of hypoxaemia was 6 seconds at the finger compared with the ear, 57 seconds at the finger compared with the toe and 63 seconds at the toe compared with the ear [9]. Conversely, Jensen, Onyskiw and Prasadclaimed that the results of pulse oximetry were more accurate at the finger in comparison with the ear [11]. Clayton et al. recommended finger probes in patients with hypoperfusion [12].

In Kelly McAlpine and Kyle's study at $\mathrm{SpO}_{2}=92 \%$, sensitivity and specificity were reported to be $100 \%$ and $86 \%$ respectively (false negatives $=0$ ); but at $\mathrm{SpO}_{2}=88 \%$ the sensitivity fell to $66.7 \%$ and specificity rose to $96.4 \%$ (false negatives $=33$ ) [13]. Our study showed that at $\mathrm{SpO}_{2}=92 \%$ we can predict (in children) that $\mathrm{SaO}_{2}$ will be $\geq 90 \%$ with a sensitivity of $67 \%, 83 \%$ and $83 \%$ and a specificity of $98 \%, 92 \%$ and $90 \%$ by placing the pulse oximetry probes at ear, thumb and big toe, respectively. 


\begin{tabular}{|c|c|c|c|c|c|}
\hline \multicolumn{6}{|c|}{$\begin{array}{l}\text { Table } 3 \text { Validity and clinical agreement of pulse oximetry readings on } 3 \text { parts of the } \\
\text { body in children and neonates }\end{array}$} \\
\hline $\begin{array}{l}\text { Age group/ } \\
\text { probe site }\end{array}$ & Sensitivity & Specificity & $\begin{array}{c}\text { Positive } \\
\text { predictive } \\
\text { value } \\
\%\end{array}$ & $\begin{array}{c}\text { Negative } \\
\text { predictive } \\
\text { value } \\
\%\end{array}$ & $\begin{array}{l}\text { Clinical } \\
\text { agreement } \\
\text { (א) }\end{array}$ \\
\hline \multicolumn{6}{|l|}{ Children } \\
\hline Ear & 67 & 98 & 80 & 96 & 0.70 \\
\hline Thumb & 83 & 92 & 56 & 98 & 0.62 \\
\hline Big toe & 83 & 90 & 50 & 98 & 0.57 \\
\hline \multicolumn{6}{|l|}{ Neonates } \\
\hline Ear & 40 & 100 & 100 & 93 & 0.54 \\
\hline Thumb & 50 & 97 & 75 & 93 & 0.55 \\
\hline Big toe & 25 & 90 & 20 & 93 & 0.28 \\
\hline
\end{tabular}

According to Bell et al.'s study, the result of the deduction $\mathrm{SpO}_{2}-\mathrm{SaO}_{2}$ was called the bias and the standard deviation for the deductions was named accuracy [14]. In the study of Uystepruyst et al. the amount of bias in general conditions was $2.1 \%$ but changed to $0.6 \%$ (SD 3.2\%) when $\mathrm{SaO}_{2}$ was > $90 \%$ [15]. It must be mentioned that bias can be negative as noted by Van de Louw et al. [-0.02 (SD 2.1)] [4]. The amount of bias in our study was 0.02 (SD 3.71) at the ear, -0.82 (SD 3.43 at the thumb and -1.94 (SD 3.18) at the big toe, which shows underestimation by the toe probe and to some extent by the finger probe, but relative overestimation by the ear probe. Besides, there were similar findings in the neonate group; bias was 1.53 (SD 3.42) at the ear and -0.45 (SD 3.90) at the toe. By considering $\mathrm{SpO}_{2}=92 \%$ in our study, the negative predictive value of the ear and thumb probes were $96 \%$ and $98 \%$ respectively in neonates and 93\% and 93\% respectively in children aged over 1 month. This means that in $96 \%$ to $98 \%$ of patients who show $\mathrm{SpO}_{2} \geq 92 \%$, their $\mathrm{SaO}_{2}$ will be $\geq 90 \%$, and therefore they are not affected with hypoxaemia. Such findings were also noted in the study of Van de Louw et al., but by considering $\mathrm{SpO}_{2}=94 \%$, the negative predictive value was $99 \%$ [4]. This means that $99 \%$ of patients with $\mathrm{SpO}_{2}>94 \%$ would have $\mathrm{SaO}_{2} \geq 90 \%$ and therefore no hypoxaemia.

One key result of our study was the low sensitivity and minimal to moderate clinical agreement of pulse oximetry with $A B G$ in neonates. It raises the question whether the light absorption characteristics of neonatal tissues are different at $\mathrm{SpO}_{2}=92 \%$. The study of Uystepruyst et al. revealed that bias and accuracy are not affected by fetal haemoglobin because the light absorption characteristics of fetal haemoglobin for wavelengths of light used in usual pulse oximeters are similar to those of adult haemoglobin [15].

\section{Conclusion}

Ourstudy showed that pulse oximetry at the toe had the lowest clinical agreement with $\mathrm{ABG}$ results in both neonates and children. However, when the probe was placed at the ear or finger of newborns or children, the result of pulse oximetry were more reliable for exclusion of hypoxaemia and correlated more closely with the $A B G$ result. This means that $96 \%$ to $98 \%$ of patients who show $\mathrm{SpO}_{2}$ $\geq 92 \%$ at the ear or finger, their $\mathrm{SaO}_{2}$ will be $90 \%$ or more, and therefore are not affected with hypoxaemia.

\section{Acknowledgements}

We wish to thank our colleagues Mrs R. Jigary (head nurse of PICU) and Miss F. Shafaei (chief respiratory nurse) for their assistance in this study.

\section{References}

1. Perkins DG et al. Do changes in pulse oximetry oxygen saturation predict equivalent changes in arterial oxygen saturation? Critical care, 2003, 7(4):67-71.

2. Witting MD, Hsu S, Granja CA. The sensitivity of room air pulse oximetry in the detection of hypercapnia. American journal of emergency medicine, 2005, 23:497-500.

3. Summer LA et al. Effects of routine pulse oximetry measurements on ED triage classification. American journal of emergency medicine, 1998, 16(1):5-7.

4. Van de Louw A et al. Accuracy of pulse oximetry in the intensive care unit. Intensive care medicine, 2001, 27:1606-13.

5. Shrake K et al. AARC (American Association for Respiratory Care) clinical practice guideline. Pulse oximetry. Respiratory care, 1991, 36:1406-9.
6. Sinex EJ. Pulse oximetry: principles and limitations. American journal of emergency medicine, 1999, 17(1):59-66.

7. Salyer WJ. Neonatal and pediatric pulse oximetry. Respiratory care, 2003, 48(4):386-98.

8. Villanueva R et al. Effects of peripheral perfusion on accuracy of pulse oximetry in children. Journal of clinical anesthesia, 1999, 11:317-22.

9. Hamber AE et al. Delays in the detection of hypoxemia due to site of pulse oximetry probe placement. Journal of clinical anesthesia, 1999, 11:113-8.

10. Moller JT et al. Randomized evaluation of pulse oximetry in 20,802 patients: II. Perioperative events and postoperative complications. Anesthesiology, 1993, 78:445-53. 
11. Jensen AL, Onyskiw EJ, Prasad NGN. Meta-analysis of arterial oxygen saturation monitoring by pulse oximetry in adults. Heart and lung, 1998, 27:387-408.

12. Clayton DG et al. Pulse oximetry probes. A comparison between finger, nose, ear and forehead probes under conditions of poor perfusion. Anaesthesia, 1991, 46(4):260-5.

13. Kelly AM, McAlpine R, Kyle E. How accurate are pulse oximeters in patients with acute exacerbations of chronic obstructive airways disease? Respiratory medicine, 2001, 95:336-40.

14. Bell C et al. Effects of probe design on accuracy and reliability of pulse oximetry in pediatric patients. Journal of clinical anesthesia, 1999, 11:323-7.

15. Uystepruyst J et al. Evaluation of accuracy of pulse oximetry in newborn calves. Veterinary journal 2000, 159:71-6.

\section{Manual for the health care of children in humanitarian emergencies}

This manual was developed based on the recommendations of a global technical consultation on child health in humanitarian emergencies co-organized by WHO and UNICEF at the end of 2003. It is a collaborative work of three technical areas within WHO: Child and Adolescent Health and Development (CAH), Health Action in Crises (HAC), and Disease Control in Humanitarian Emergencies (DCE).

The objective of the manual is to provide comprehensive guidance on child care in emergencies. Existing guidelines, such as IMCI, assume a functioning health system that facilitates the referral of children, which may not be available in emergency situations. So this manual also includes the initial management of severe conditions. It was also realized that existing manuals do not cover injuries, burns, neonatal illness, psychosocial problems etc, which are considered of high priority in emergency settings. These are addressed along with issues on mental health, psychosocial support and common preventive interventions such as immunization.

Each chapter summarizes the main ways of diagnosis, treatment and prevention using flow charts. The flow charts are arranged in such a way that they can be enlarged for use as job aids/wall charts, or for modular training at convenient times on the management of each condition.

The manual is available in English and French at: http://www.who.int/child_adolescent_health/ documents/9789241596879/en/index.html 